\title{
Carvacrol release from PLA to a model food emulsion: Impact of oil droplet size
}

\author{
Li Wang ${ }^{\mathrm{a}}$, Matthijs Dekker ${ }^{\mathrm{a}, *}$, Jenneke Heising ${ }^{\mathrm{a}}$, Vincenzo Fogliano ${ }^{\mathrm{a}}$, Claire C. Berton-Carabin ${ }^{\mathrm{b}}$ \\ ${ }^{a}$ Food Quality and Design, Bornse Weilanden 9, 6708 WG, Wageningen, the Netherlands \\ ${ }^{\mathrm{b}}$ Laboratory of Food Process Engineering, Wageningen University \& Research, Bornse Weilanden 9, 6708 WG, Wageningen, the Netherlands
}

\section{A R T I C L E I N F O}

\section{Keywords:}

Carvacrol

Antimicrobial packaging

Emulsion

Oil droplet size

Partitioning

\begin{abstract}
A B S T R A C T
The effect of food structure on the release of a volatile antimicrobial from an active packaging (AP) was investigated by measuring the migration of carvacrol from a polylactic acid (PLA) film to a model food system, namely, an oil-in-water $(\mathrm{O} / \mathrm{W})$ emulsion. We aimed to understand the influence of the oil droplet size on the kinetics of carvacrol migration from the PLA film to the emulsions, on its final partitioning and antimicrobial activity. Five model systems were prepared: they had the same composition, i.e., an oil fraction of $20 \mathrm{wt} \%$ and an aqueous phase containing $1.5 \mathrm{wt} \%$ whey protein isolate, but different structures.

Emulsions with the smallest oil droplets $\left(d_{3,2}=0.27 \mu \mathrm{m}\right)$ absorbed a higher amount of carvacrol than emulsions with large oil droplets $\left(d_{3,2}=0.34 \mu \mathrm{m}\right.$ and $\left.d_{3,2}=0.51 \mu \mathrm{m}\right)$. Despite the higher overall carvacrol concentration, inhibition of bacterial growth was less effective in emulsions with the smallest droplet $\left(d_{3,2}=0.27 \mu \mathrm{m}\right)$. This can be explained by the highest $\log K$ of carvacrol in this emulsion indicating that carvacrol partitioned more into the oil droplet phase than in the continuous phase.

The current study suggests that the spatial distribution of carvacrol in the emulsion determines its actual antimicrobial effect. The combined findings of antimicrobial distribution and activity highlight the need for tailoring active packaging systems based on the physical characteristics of multiphase food matrices.
\end{abstract}

\section{Introduction}

Reduction of food waste is necessary to combat hunger, raise income and improve food security in developing or low-income countries (FAO, 2011). Food loss through microbial spoilage is an important concern to both consumers and food industries, which has resulted in an increased interest in antimicrobial packaging (AP) to increase the shelf-life and safety of foods. AP is a form of active food packaging, which is developed by incorporating specific active agents into packaging films. AP can reduce the growth rate and extend the lag phase of target microorganisms in packed foods, thereby prolonging the shelflife of foods (Mihindukulasuriya \& Lim, 2014). The growth of microorganisms can be inhibited either by direct contact between the food product and a packaging film loaded with non-volatile antimicrobials, or by indirect contact, when the packaging releases volatile compounds in the headspace. In the latter case, evaporation or equilibrated distribution of the antimicrobials between the headspace, packaging material and/or food has to be considered to understand the activity of the antimicrobials (Quintavalla \& Vicini, 2002).

Many food systems contain simultaneously liquid, solid and gaseous phases which can form a broad range of colloidal structures. Therefore, food matrices have very different physical properties, which, in turn, may influence the partitioning and mass transport of antimicrobials added in a food packaging system (Weiss, Loeffler, \& Terjung, 2015). In order to develop an effective AP, several factors should be considered such as the intrinsic properties of the polymer films, the mass transfer coefficients of active substances, the storage conditions and finally the food matrix characteristics (Han, 2003). In the past decades, many AP products were developed combining novel plastic materials and new antimicrobial compounds (Sung et al., 2013). The strategies to control the release and migration of active compounds from packaging films to either model or real foods were investigated in all details (de Azeredo, 2013; Jideani \& Vogt, 2016). However, the influence of the food matrix itself (composition and physical structure) on the efficiency of AP is largely unexplored.

Many food products are oil-in water (O/W) emulsions, which consist of lipid droplets dispersed in an aqueous medium, e.g. milk, yogurt or salad dressing. They may have a broad range of droplet sizes, from submicron to around $100 \mu \mathrm{m}$ (McClements, 2015). Droplet size plays an important role for the stability, rheology, appearance, color and texture

\footnotetext{
* Corresponding author. PO Box 17, 6700AA, Wageningen, the Netherlands.

E-mail address: matthijs.dekker@wur.nl (M. Dekker).
} 
A

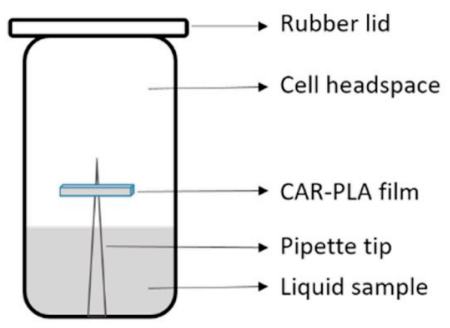

B

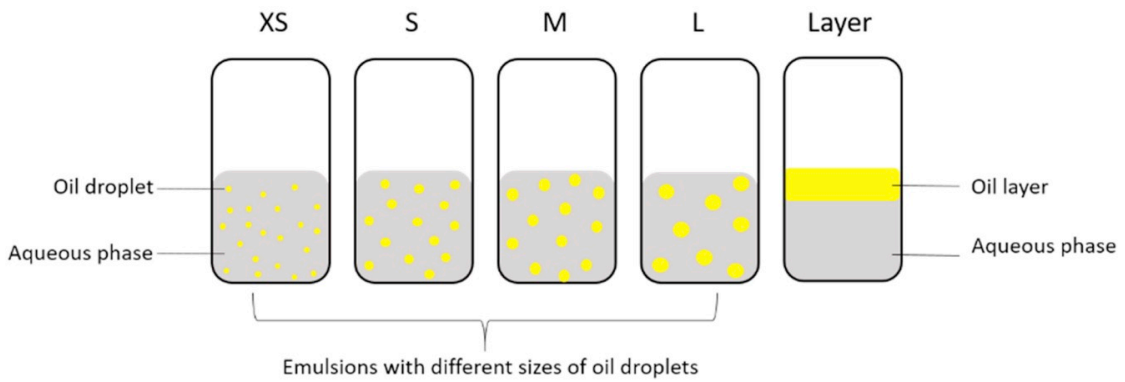

Fig. 1. Scheme illustration of the set-up used to evaluate carvacrol partitioning between a packaging film and a liquid food matrix, separated by a gas phase (A), and scheme of the different liquid samples (B).

of emulsions (Becher, 2001; Jafari, Assadpoor, He, \& Bhandari, 2008; McClements, 2005). Flavour release studies investigated the effect of droplet size on volatile compounds release from emulsions (de Roos, 2003; Doi, Wang, \& McClements, 2019; Soottitantawat, Yoshii, Furuta, Ohkawara, \& Linko, 2003). Benjamin, Silcock, Leus, and Everett (2012) found an increase in volatile organic compound (VOC) release from unstable emulsions (aggregated droplets) at $\mathrm{pH}$, compared to stable emulsions (finely distributed droplets) at the same $\mathrm{pH}$. These studies have shown that flavour retention is influenced by the amount of oilwater interfacial area present in emulsions. This is relevant to the present study, as flavour release and retention from emulsions is simply the opposite process of the absorption and partitioning of volatile antimicrobials from packaging materials into emulsions. Antimicrobial distribution in a food matrix is important as it can be hypothesized that the location of antimicrobial molecules determines their efficiency. However, the effect of the oil droplet size on the antimicrobial partitioning in a food package containing emulsions has not yet been reported.

In this work, we used carvacrol as model antimicrobial agents as it is a volatile compound, which has proved useful to prevent the growth of bacteria (Periago, Delgado, Fernández, \& Palop, 2004), mold (Daferera, Ziogas, \& Polissiou, 2003) and yeast (Arora \& Kaur, 1999). Carvacrol has recently been incorporated in methyl cellulose (MC) (Tunc, Duman, \& Polat, 2016), wheat gluten (Mascheroni, Chalier, Gontard, \& Gastaldi, 2010), and sodium-calcium caseinate films (Altan, Aytac, \& Uyar, 2018). As packaging material, polylactic acid (PLA) was chosen: PLA is a renewable and biodegradable source that holds great potential for packaging applications due to its good mechanical and barrier properties (Mlalila, Hilonga, Swai, Devlieghere, \& Ragaert, 2018). Carvacrol-loaded PLA films, besides being a good model, also have a good potential to be used on large scale in food preservation (Ahmed, Hiremath, \& Jacob, 2016).

In this work, we investigated the migration of carvacrol from a PLA film to a model multiphase food system (emulsions), occurring via a surrounding air phase (headspace). Sunflower $\mathrm{O} / \mathrm{W}$ emulsions with a fixed fraction of oil but various oil droplet sizes were considered as model foods, and exposed to indirect contact with carvacrol-loaded PLA films. The aims of this work were to unravel the influence of the oil droplet size on carvacrol partitioning between the available phases, and to further examine the impact of the antimicrobial partitioning on its efficiency at the bacterial growth inhibition in the model food matrix.

\section{Materials and methods}

\subsection{Materials}

PLA (4043D Ingeo ${ }^{\mathrm{TM}}$ ) was kindly supplied by the Food \& Biobased Research institute of Wageningen University and Research (Netherlands). Carvacrol ( $\geq 98 \%$ ), dichloromethane (DCM), hexane and 2-propanol were purchased from Sigma Aldrich (Pty. Ltd., Netherlands). Whey protein isolate (WPI, $\geq 95 \%$ protein) was obtained from Davisco (Lancy, Switzerland). Sunflower oil was purchased from a local supermarket and used without further purification. Plate count agar (PCA) was purchased from Merck (Schiphol-Rijk, Netherlands). Peptone physiological salt solution (PFZ) was purchased from Tritium Microbiologie BV (Eindhoven, Netherlands).

\subsection{Preparation of the carvacrol-loaded PLA film}

The solvent-casting method was used to prepare a carvacrol-loaded PLA film (CAR-PLA) (Rhim, Mohanty, Singh, \& Ng, 2006). Briefly, PLA pellets ( $4 \mathrm{~g}$ ) were completely dissolved in DCM (25 mL DCM/g of PLA) by gentle stirring at $20^{\circ} \mathrm{C}$ for $6 \mathrm{~h}$. One gram of carvacrol was then added to the solution and stirred for $1 \mathrm{~h}$ at room temperature $\left(20{ }^{\circ} \mathrm{C}\right)$. The carvacrol/PLA/DCM solution was sonicated with an ultra-sonicator (HBM Machines, Moordrecht, the Netherlands) at $40 \mathrm{kHz}$ for $30 \mathrm{~min}$ to further homogenize the solution. Subsequently, $20 \mathrm{~mL}$ of the solution was cast on a glass petri dish (size $100 \times 15 \mathrm{~mm}$ ) and allowed to dry at room temperature overnight. The film was peeled from the glass petri dish, and was stored at $4{ }^{\circ} \mathrm{C}$ in a sealed glass container.

\subsection{Preparation and characterization of liquid samples}

Five model liquid samples were prepared, including three types of fine emulsions (with very small, small, and small-medium oil droplets, abbreviated as XS, S, and M, respectively), one coarse emulsion (with large oil droplets, abbreviated as L) and a non-homogenized sample, consisting of separate layers of aqueous phase and oil (Fig. 1B). All the samples contained the same concentration of emulsifier (WPI) and sunflower oil, they thus differed only in the oil droplet size, and accordingly, in the amount of oil-water interfacial area.

\subsubsection{Preparation of emulsions}

The fine emulsions (XS, S, and M) were prepared by high pressure homogenization. A whey protein solution was prepared by dispersing $1.5 \mathrm{~g}$ of whey protein isolate into $80 \mathrm{~mL}$ ultrapure water ( $\mathrm{pH} \mathrm{6.7).} \mathrm{The}$ mixture was dissolved under slow magnetic stirring for $2 \mathrm{~h}$. It was then kept overnight at $4{ }^{\circ} \mathrm{C}$ to allow for complete hydration. Sunflower oil was then added to the protein solution to form an oil-in-water emulsion with $20 \mathrm{wt} \%$ sunflower oil. The mixture was pre-emulsified by using a rotor-stator homogenizer (Ultra-Turrax, IKA ${ }^{\circledR}$-Werke GmbH \& Co. KG, Staufen, Germany) at 11,000 rpm for $1 \mathrm{~min}$. The obtained pre-emulsion was then passed through a high pressure homogenizer (Microfluidizer Processor MF 110Y with Y-shaped interaction chamber (F12Y; min. internal channel: $75 \mu \mathrm{m}$ ), Microfluidics, Newton, Massachusetts, USA) at $1 \times 10^{4}, 4 \times 10^{4}$ or $8 \times 10^{4} \mathrm{kPa}$ (for M, S, and XS emulsions, respectively) for 5 cycles. For the coarse emulsion (referred to as $\mathrm{L}$ ), we processed the pre-emulsion with a colloid mill (Homogenizer MagicLab, 
IKA $^{\circledR}$-Werke GmbH \& Co. KG, Staufen, Germany) equipped with a MK module at $26,000 \mathrm{~min}^{-1}$ for $5 \mathrm{~min}$.

\subsubsection{Physical characterization of emulsions}

Particle size distribution. The droplet size and size distribution of emulsions were analyzed by laser static light scattering (Malvern Mastersizer 3000, Malvern Instruments Ltd, Malvern, Worcestershire, $\mathrm{UK})$ after $3 \mathrm{~h}(\mathrm{t}=3 \mathrm{~h})$ and 7 days $(\mathrm{t}=7 \mathrm{~d})$ storage. The refractive indices (RI) were 1.46 (oil) and 1.33 (water) with an adsorption index of 0.01 . The average droplet size was expressed as the Sauter diameter $\left(d_{3,2}\right)$. Emulsions were diluted 10 times in $1 \mathrm{wt} \%$ sodium dodecylsulfate (SDS) solution to separate any flocculated oil droplets.

Creaming stability of the coarse emulsion. The kinetics of cream layer formation was determined in the coarse emulsion (for the fine emulsions, no noticeable creaming was detected over the timescale of the experiments). The height of the creamed layer was recorded during 7 days incubation in steady conditions at $20{ }^{\circ} \mathrm{C}$. Equation (1) was used to fit the increase in height of the cream layer as a function of storage time. The maximum cream height in emulsion is noted $H_{\max }(\mathrm{mm}) . D_{t}$ (day) is the storage time needed to achieve $50 \%$ of the maximum cream height.

$H=\frac{H_{\max } * t}{D_{t}+t}$

Whey protein surface load. Emulsion samples were centrifuged at $21191 \times g$ for $2 \mathrm{~h}$ to separate the creamed and serum phases. Protein content in the serum was quantified by the bicinchoninic acid (BCA) assay (Pierce BCA protein assay, Thermo Fisher Scientific lnc., Rotterdam, Netherlands). The protein surface load $(\Gamma)$ was determined by considering the initial protein concentration in the starting WPI solution $\left(C_{i}\right)$, the free protein concentration in the serum phase $\left(C_{s}\right)$, the dispersed phase volume fraction $(\varphi)$ and the mean particle diameter $\left(d_{3,2}\right)$ (Eq. (2)) (Berton, Genot, \& Ropers, 2011; McClements, 2004):

$\Gamma=\left(C_{i}-C_{s}\right) * d_{32} / 6 \varphi$

The total interfacial area $(S)$ was obtained following Berton, Ropers, Viau, and Genot (2011) (Eq. (3)):

$S=S_{\text {droplet }} * m_{\text {oil }} /\left(V_{\text {droplet }} * \rho\right)$

In which $S_{\text {droplet }}$ represents the surface area of one fat droplet (obtained from the $\left.d_{3,2}\right), m_{\text {oil }}$ is the mass of oil in the same emulsion, $V_{\text {droplet }}$ is the volume of one oil droplet (obtained from the $d_{3,2}$ ) and $\rho$ is the density of oil ( $\rho=0.924$ for sunflower oil according to Borges, Díaz, Alvarez-Galván, and Brito (2011)).

\subsection{Quantification of carvacrol in the different phases of the system}

\subsubsection{Calibration}

To quantify the amount of carvacrol in the headspace of the vial and in the liquid sample, a stock solution of carvacrol in n-hexane:isopropanol (3:1) was prepared at a concentration of $2.0 \mathrm{mg} / \mathrm{mL}$. Five concentrations between $0.4 \mathrm{mg} / \mathrm{mL}$ and $2.0 \mathrm{mg} / \mathrm{mL}$ were prepared by diluting the stock solution. These calibration solutions were then injected and analyzed by GC-FID (see next section). Within this concentration range, a linear calibration curve was obtained with a coefficient of correlation of 0.9996 .

\subsubsection{Headspace gas chromatography (HS-GC-FID)}

The carvacrol concentration in the headspace of the vials was measured using gas chromatography coupled with a flame ionization detector (GC-FID) (Thermo Scientific, Waltham, Massachusetts, United States). The method to directly collect carvacrol from the headspace of glass vials was adapted from Higueras, López-Carballo, HernándezMuñoz, Catalá, and Gavara (2014) with some modifications. Briefly, a 2.5-mL syringe (Hamilton, Bonaduz, Switzerland) was used to pierce the rubber lid of glass vial, then collect $500 \mu \mathrm{L}$ headspace which were immediately injected into the GC-FID injection port. The amount of carvacrol present in the headspace was calculated from the aforementioned external calibration curve.

The followings conditions were used to operate GC-FID: the injection temperature was set at $250{ }^{\circ} \mathrm{C}$. The column oven temperature was initially set to $60{ }^{\circ} \mathrm{C}$, then increased to $250{ }^{\circ} \mathrm{C}$ with a rate of $15{ }^{\circ} \mathrm{C}$ $\min ^{-1}$. Helium was used as the carrier gas, running at a constant flow of $2.0 \mathrm{~mL} \mathrm{~min}{ }^{-1}$. The FID was operated with a hydrogen flow of $35 \mathrm{~mL} \mathrm{~min}^{-1}$ and an air flow of $300 \mathrm{~mL} \mathrm{~min}^{-1}$. The total running time was $25.25 \mathrm{~min}$.

\subsubsection{Extraction and quantification of carvacrol in liquid samples}

Carvacrol extraction from liquid samples was optimised based on the method of (Lu, Pickova, Vázquez-Gutiérrez, \& Langton, 2018). To extract carvacrol from the whole emulsion, $4 \mathrm{~mL}$ solvent (n-hexaneisopropanol, $3: 1, \mathrm{v} / \mathrm{v}$ ) were added to $2 \mathrm{~mL}$ sample. For quantification of carvacrol in the creamed and serum phases, the emulsions were first centrifuged for $2 \mathrm{~h}$ at $21191 \times g$ to separate the phase of emulsion, as described above. Three or one millilitres extraction solvent (hexane:isopropanol, $3: 1 \mathrm{v} / \mathrm{v}$ ) were then added to the cream or serum phase, respectively, to extract carvacrol from each phase. The mixtures were vortexed for $1 \mathrm{~min}$ at room temperature $(3000 \mathrm{rpm})$, followed by heating in a heating block at $60^{\circ} \mathrm{C}$ for $30 \mathrm{~min}$. Then the organic phase $(10 \mu \mathrm{L})$ was injected into GC-FID for quantification of the carvacrol concentration. A high extraction yield ( $>96 \%$ ) was achieved by using this extraction method, which ensured a complete extraction of carvacrol from emulsion samples.

\subsubsection{Determination of the partition coefficient of carvacrol between lipid} and aqueous phases

The partition coefficient $(\log K)$ of carvacrol was calculated as (Eq. (4)):

$\log K_{\text {cream/aqueous }}=\log \frac{C_{\text {cream }}}{C_{\text {aqueous }}}$

Where $C_{\text {cream }}$ is the concentration of carvacrol in the creamed phase (mg/mL), and $C_{\text {aqueous }}$ is the concentration of carvacrol in aqueous phase of samples $(\mathrm{mg} / \mathrm{mL})$.

\subsection{Microbiological analyses of emulsions}

\subsubsection{Microbial strain}

The strain Pseudomonas fluorescens ATCC 13525 was provided by the Food Microbiology Group of Wageningen University (the Netherlands). It was cultured in nutrient broth (Merck BV, Schiphol-Rijk, the Netherlands) at $30{ }^{\circ} \mathrm{C}$ for $48 \mathrm{~h}$ from stock culture.

\subsubsection{Thermal treatment of emulsions}

Fine emulsions were sterilized prior to the antimicrobial test by a applying a thermal treatment at $72{ }^{\circ} \mathrm{C}$ for $10 \mathrm{~min}$. After thermal treatment, samples were immediately cooled in an icebox.

\subsubsection{Preparation of samples}

After thermal treatment, liquid samples were inoculated with Pseudomonas fluorescens to obtain a final concentration of $10^{4} \mathrm{CFU} / \mathrm{mL}$. Fine emulsions were divided into three groups according to the size of oil droplet (XS, S and M). Each group was then subdivided into antimicrobial group and control group. In each antimicrobial group, an emulsion aliquot $(2 \mathrm{~mL})$ was stored with the CAR-PLA film $(0.02 \mathrm{~g}$ in each vial; Fig. 1A). All samples were prepared in individual sterilized glass vials for each periodical measurement $(0,0.5,1,1.5,3,5$, and 7 days), and stored at $20{ }^{\circ} \mathrm{C}$. 


\subsubsection{Enumeration of bacteria}

The enumeration of Pseudomonas fluorescens was performed by using the pour plate method. At each sampling day, bacterial population was determined by serially diluting $1 \mathrm{~mL}$ of emulsion in $9 \mathrm{~mL}$ of peptone physiological salt solution (PFZ) and plating $100 \mu \mathrm{L}$ on plate count agar (PCA). The microplates were cultured at $30{ }^{\circ} \mathrm{C}$ for $24 \mathrm{~h}$ before counting the number of bacterial colonies.

\subsubsection{Microbial growth modeling}

A modification of the model developed by Gompertz as used to fit the bacterial growth curves. This modified Gompertz equation (Eq. (5)) described the total viable count of bacteria in samples as a function of time(Zwietering, Jongenburger, Rombouts, \& Van't Riet, 1990).

$\ln \frac{N}{N_{0}}=A_{s}{ }^{*} \exp \left(-\exp \left(\frac{\mu_{\max } e}{A_{s}}(\lambda-t)+1\right)\right)$

Herein, $A_{S}$ is the natural logarithm of the asymptotic value of the relative population size $\left(\log (\mathrm{CFU} / \mathrm{mL}), u_{\max }\right.$ is the maximum specific growth rate $\left(\right.$ day $\left.^{-1}\right), \lambda$ is the duration of the lag phase (day), $t$ is the storage time (day) and $N / N_{0}$ represents the ratio of the microbial cell density ( $\mathrm{CFU} \mathrm{mL}{ }^{-1}$ ) to the initial microbial cell density $\left(\mathrm{CFU} \mathrm{mL}{ }^{-1}\right.$ ).

\subsection{Experimental design}

The carvacrol partitioning and antimicrobial activity were studied in a closed set-up designed to mimic a situation where migration of volatile molecules may occur between a packaging film and a food matrix separated by a gas phase (Fig. 1A). This system thus consisted of a $20-\mathrm{mL}$ Verex ${ }^{\mathrm{TM}}$ headspace vial containing $2 \mathrm{~mL}$ of liquid sample, and a piece of CAR-PLA film $(0.020 \pm 0.001 \mathrm{~g})$ mounted on a pipette tip to prevent direct contact with the liquid sample. Vials were sealed by a rubber lid to prevent gas leaking. Several vials with the same weight of packaging film and same volume of sample were prepared for daily measurement of carvacrol absorption in the food matrix. All samples were stored at room temperature $\left(20^{\circ} \mathrm{C}\right)$.

\subsection{Statistical analysis}

All experiments were performed in independent duplicates, and measurements were performed in triplicate. Data were expressed as mean \pm standard deviation of triplicate measurements. For the statistical analysis, the IBM SPSS Statistics software, version 23.0 for Windows (Armonk, NY: IBM Corp) was used. One-way analysis of variance (ANOVA), with post-hoc pairwise analysis by the Tukey test was used to evaluate the significant differences between samples. A significant difference between results was determined when $p<0.05$. The parameters of Eqs. (1) and (5) were estimated with the lowest mean square error (MSE), where the maximum cream height in emulsion $H_{\max }(\mathrm{mm})$, the storage time needed to achieve $50 \%$ of the maximum cream height $D_{t}$ (day), maximum growth rate $\mu$ (day $^{-1}$ ), lag phase duration $\lambda$ (day) and $A_{s}(\log (\mathrm{CFU} / \mathrm{mL})$ were obtained.

\section{Results and discussion}

\subsection{Physical stability of emulsions}

The particle size distribution of emulsions shortly after preparation $(t=3 \mathrm{~h})$ and after 7 days storage is shown in Fig. 2. The size distributions for the three fine emulsions were unimodal with an average diameter $\left(d_{3,2}\right)$ ranging from 0.27 to $0.51 \mu \mathrm{m}$. They remained constant over the timescale of the experiment (Fig. 2B), indicating a good physical stability of those emulsions. For the emulsion produced by colloid mill homogenization, a larger mean particle size was obtained $\left(d_{3,2}\right.$ $\sim 2.75 \mu \mathrm{m}$ ). The droplet size distribution of this coarse emulsion, shortly after preparation, shows two distinct peaks, revealing a large polydispersity. After 7 days storage, a shoulder was visible around $50-100 \mu \mathrm{m}$ and the droplets at this range of scale did not disappeared in the 1 wt $\%$ of SDS solution, which means that some coalescence occurred in the coarse emulsion.

Fig. 3 shows the kinetics of the cream layer formation in the coarse emulsion during storage. Fast creaming was observed within the first day following sample preparation, and $50 \%$ of the maximum height of the final cream layer were reached after $8.5 \mathrm{~h}$. This is due to the propensity of large emulsion droplets to experience fast gravitational separation in dilute media, according to the Stokes' law (Stokes, 1851). After 2 days storage, the height of the cream layer increased only minimally, mainly owing to smaller oil droplets. This substantial creaming phenomenon in the coarse emulsion had relevant implications for our study. First, creaming brings droplets in close proximity and may promote droplet coalescence, hence altering the droplet size. Second, it leads to macroscopic separation between the serum and creamed phases, and hence to structural heterogeneity of the sample, which may have implications regarding how and how fast molecules partition between the available environments, which will be discussed in more depth later.

The partitioning of proteins within the emulsion phases was also determined (Table 1). In all emulsions, a large fraction of the total protein used remained non-adsorbed in the aqueous phase (from $64 \%$ for the XS-sized emulsion, to $89 \%$ for the L-sized emulsion). The protein surface load ranged between $0.92 \mathrm{mg} / \mathrm{m}^{2}$ and $1.52 \mathrm{mg} / \mathrm{m}^{2}$ for the fine emulsions. A significantly larger value was measured in the coarse emulsion $\left(\Gamma=3.13 \mathrm{mg} / \mathrm{m}^{2}\right)(p<0.05)$, which could be a result of the different homogenization procedure used between fine and coarse emulsions. These values are in line with data reported in other publications (Berton-Carabin \& Schroën, 2015; Dresselhuis, Stuart, van Aken, Schipper, \& de Hoog, 2008; Keppler, Steffen-Heins, BertonCarabin, Ropers, \& Schwarz, 2018; McClements, 2015).

\subsection{Carvacrol partitioning between PLA film, headspace and emulsion}

In our experimental set-up (Fig. 1), carvacrol was initially included in the PLA film, and first migrates to the headspace of the hermetically sealed tube, through which it can then reach the emulsion sample. Fig. 4A shows the carvacrol concentration in the headspace over 7 days storage. For all samples, a fast release of carvacrol from the PLA-CAR films to the headspace occurred rapidly after the beginning of the storage. The highest concentration of carvacrol in the headspace was found at day 1 for most samples, except for the emulsion prepared by high pressure homogenization at $1 \times 10^{4} \mathrm{kPa}$ (M-sized) where it was already reached after $12 \mathrm{~h}$. After this initial stage, the carvacrol concentration in the headspace slowly decreased for all systems as consequence of its absorption in the emulsion phase. At the end of the storage period (7 days), it was around $0.16-0.18 \mu \mathrm{g} / \mathrm{mL}$ in all tubes, suggesting that the systems were getting close to an equilibrium, although for most systems it was still slowly decreasing. The differences between samples regarding the carvacrol concentration in the headspace were most obvious during the first 3 days, and ranked, from high to low, as follows: M, S, XS, L and separate oil-aqueous layer system. Significantly higher concentrations of carvacrol were found in the headspace of the tubes containing the three fine emulsions, compared with the tubes containing the coarse emulsion or separate oil and aqueous layers. The carvacrol in the headspace of emulsion $\mathrm{M}$ was significantly higher than that in the headspace of emulsions $S$ and XS during the first 2 days $(p<0.05)$; after day 3 the differences were not significant anymore $(p>0.05)$.

Next to the headspace concentration, the concentration of carvacrol absorbed in the liquid samples was quantified (Fig. 4B). The highest amount of carvacrol was measured during incubation in the sample containing the separate layers. A comparison of carvacrol absorption in XS-, S- and M-sized emulsions showed that the highest concentration of carvacrol at the end of the storage was measured in the XS-sized 
A

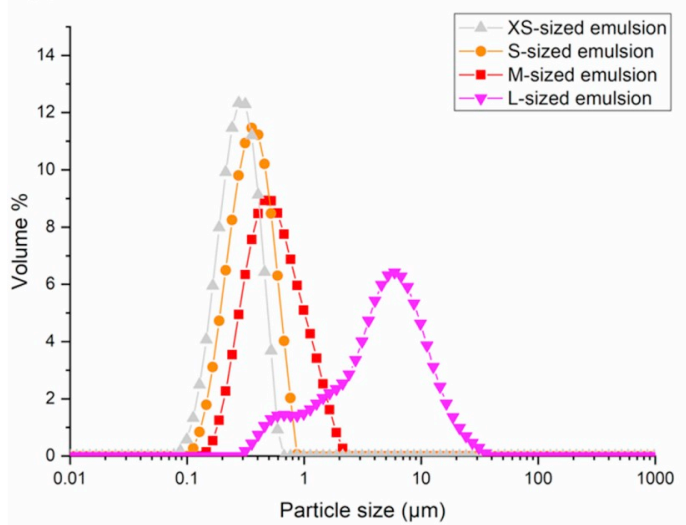

B

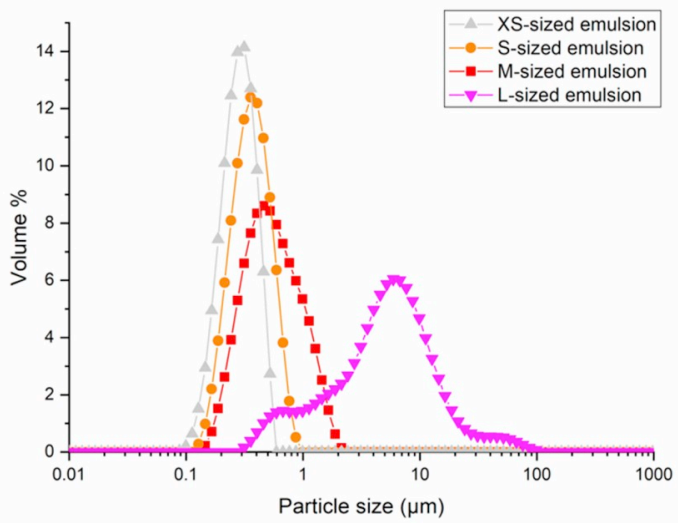

Fig. 2. Particle size distribution of oil droplets in the emulsions at $t=3 \mathrm{~h}(\mathrm{~A})$ and $t=7 \mathrm{~d}(\mathrm{~B})$.

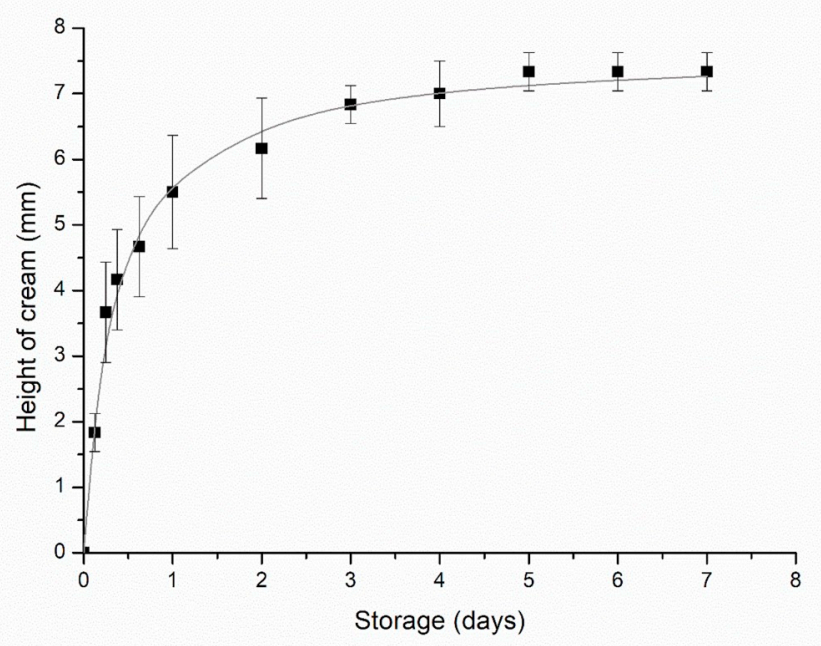

Fig. 3. Kinetics of creamed layer formation in the coarse emulsion during storage. The black solid line represents the data fit using equation (1). Error bars represent the standard deviation of 3 measurements.

emulsion $(p<0.05)$. The carvacrol concentration in the S-sized emulsion was significantly higher than that in the M-sized emulsion, and it was significantly lower than that in the XS-sized emulsion from day 2 to day 7 ( $p<0.05$ ). The M-sized emulsion absorbed $22 \%$ less carvacrol compared to the XS-sized emulsion at day 7. Regarding carvacrol absorption in the L-sized emulsion, a two-step change in the carvacrol absorption pattern was found. A fast-increasing concentration was observed at day 1 , followed by a reduced increase rate (period 1). Then a second fast increase started from day 2 until day 5 , followed by a slower increase, approaching the equilibrium, after day 5 (period 2). During the first period, the carvacrol absorption in the L-sized emulsion was fairly comparable to that in the S- and M-sized emulsions, and was significantly lower than that in the separate layer sample $(p<0.05)$. Yet a large increase of carvacrol concentration in the L-sized emulsion was found over period 2, and the carvacrol absorption became higher than in all fine emulsions after day 3. After 7 days, the carvacrol absorption in the L-sized emulsion was similar to the carvacrol absorbed in the layer sample $(p>0.05)$.

Lipid droplets in emulsions are the major reservoirs for volatile antimicrobials, which often have high $\log P$ values. Since carvacrol is a hydrophobic compound with a $\log P$ of 3.52 (Ben Arfa, Combes, Preziosi-Belloy, Gontard, \& Chalier, 2006), it will tend to partition in the oil phase of emulsions. For the data set obtained with fine emulsions (XS-, S- and M-sized emulsions), the carvacrol concentration in emulsions increased with decreasing oil droplet size, that is, with increasing interfacial area. This suggests that in the process of carvacrol transfer from the PLA film, to the headspace, to the emulsion's continuous (aqueous) phase, to the lipid droplets, the contact area between oil and water is the limiting factor. Accordingly, when the liquid sample was a layer of oil on top of a layer of aqueous phase (i.e., same overall composition, but favored contact between oil and the headspace), a rapid uptake of carvacrol in the liquid sample was found. At first sight, the observations made for the coarse emulsion seem to contradict the aforementioned droplet size effect, as the emulsion showed a rapid uptake of carvacrol despite the large droplet size, and hence limited oilwater interfacial area. However, this emulsion underwent rapid creaming, meaning that large oil droplets accumulated at the surface of the emulsion layer. In this case, the promoted contact of the creamed oil droplets with the headspace, and with neighboring droplets could have counteracted the low oil-water interfacial area, probably by-passing the transfer through the emulsion's continuous phase. The two-stage absorption behavior could therefore be explained by a combination of two mechanisms: droplet size was responsible for the moderate absorption in comparison with fine emulsions during period 1 ; and the cream layer formation could explain the increase in carvacrol absorption rate observed after 2 days storage.

Literature on the partitioning kinetics of other hydrophobic

Table 1

Initial protein concentrations, protein concentrations in the continuous phase of emulsions, volume-surface mean diameter $\left(d_{3,2}\right)$, surface load $(\Gamma)$ and total surface area of emulsions $(S)$. Data represent the mean \pm standard deviation of 3 measurements on 2 independent replicates.

\begin{tabular}{lllllll}
\hline Emulsions & $\begin{array}{l}\text { Protein initial concentration in a } \\
\text { aqueous solution }(\mathrm{mg} / \mathrm{mL})\end{array}$ & $\begin{array}{l}\text { Protein concentration in continuous } \\
\text { phase of emulsion }(\mathrm{mg} / \mathrm{mL})\end{array}$ & $\mathrm{D}_{3,2}(\mu \mathrm{m})$ at $\mathrm{t}=3 \mathrm{~h}$ & $\mathrm{D}_{3,2}(\mu \mathrm{m})$ at $\mathrm{t}=7 \mathrm{~d}$ & $\Gamma\left(\mathrm{mg} / \mathrm{m}^{2}\right)$ at t $=3 \mathrm{~h}$ & $\mathrm{~S}\left(\mathrm{~m}^{2} / \mathrm{g}\right)$ at t \\
& & $8.02 \pm 0.16^{\mathrm{a}}$ & $0.27 \pm 0.00^{\mathrm{a}}$ & $0.28 \pm 0.00^{\mathrm{a}}$ & $1.01 \pm 0.06^{\mathrm{a}}$ & $0.30 \pm 0.00^{\mathrm{a}}$ \\
$\mathrm{XS}$ & $12.52 \pm 0.12^{\mathrm{a}}$ & $9.10 \pm 0.11^{\mathrm{bc}}$ & $0.34 \pm 0.00^{\mathrm{b}}$ & $0.35 \pm 0.01^{\mathrm{b}}$ & $0.94 \pm 0.02^{\mathrm{b}}$ & $0.24 \pm 0.00^{\mathrm{b}}$ \\
$\mathrm{S}$ & $12.46 \pm 0.02^{\mathrm{a}}$ & $9.12 \pm 0.05^{\mathrm{c}}$ & $0.51 \pm 0.00^{\mathrm{c}}$ & $0.50 \pm 0.00^{\mathrm{c}}$ & $1.35 \pm 0.17^{\mathrm{c}}$ & $0.16 \pm 0.00^{\mathrm{c}}$ \\
$\mathrm{M}$ & $12.30 \pm 0.33^{\mathrm{a}}$ & $11.10 \pm 0.25^{\mathrm{d}}$ & $2.75 \pm 0.00^{\mathrm{d}}$ & $2.65 \pm 0.05^{\mathrm{d}}$ & $3.13 \pm 0.54^{\mathrm{d}}$ & $0.03 \pm 0.00^{\mathrm{d}}$ \\
$\mathrm{L}$ & $12.47 \pm 0.06^{\mathrm{a}}$ & &
\end{tabular}

Different letters (a, b, c and d) in a column indicate significant differences $(p<0.05)$. 


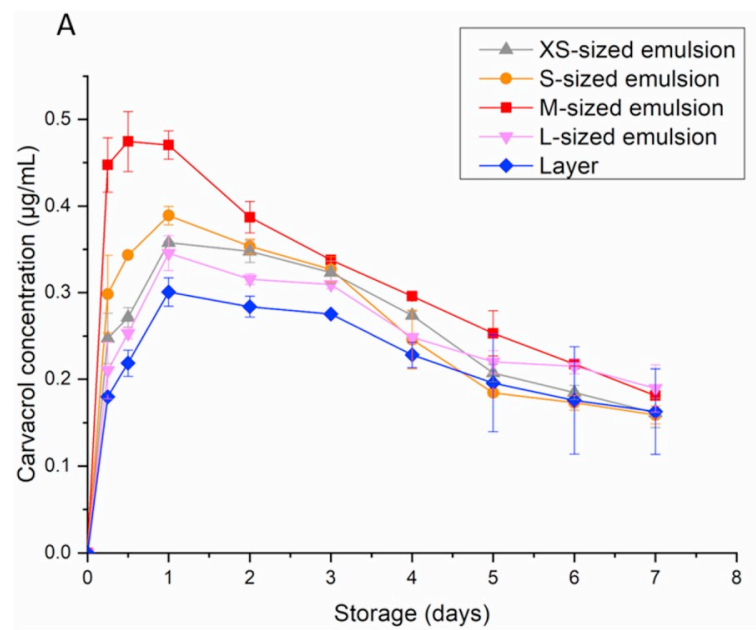

B

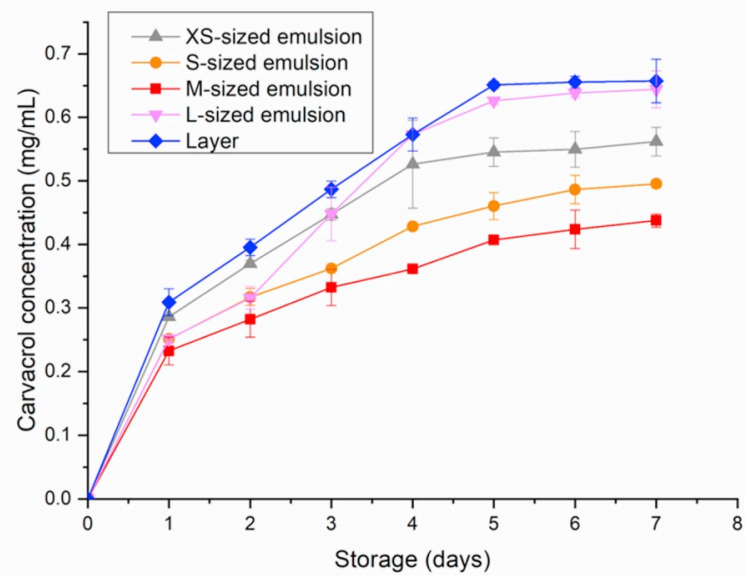

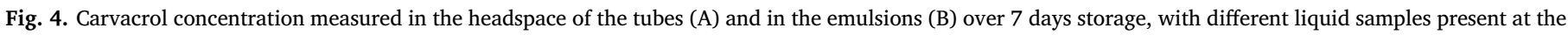
bottom of the tube (XS-, S-, M- or L-sized emulsions; or "layer" = separate layers of aqueous phase and oil).

compounds, such as flavors, provides some relevant insights for comparison with our findings. Yucel, Elias, and Coupland (2012) used electron paramagnetic resonance (EPR) to determine the distribution of a model hydrophobic compound (4-phenyl-2,2,5,5-tetramethyl-3-imidazoline-1-oxyl nitroxide, PTMIO) between phases in emulsions, and they found an increased proportion of PMTIO in the aqueous environment of emulsions with decreasing the droplet size. The results were explained by two mechanisms. First, a greater interfacial area would promote interaction between PTMIO and the protein-covered droplet surface. Alternatively, the Laplace pressure increases with decreasing droplet size, leading to an increased solubility of the lipophilic spin probe in the aqueous layer immediately surrounding the droplets. These results are well in line with ours. Moreover, Carey, Asquith, Linforth, and Taylor (2002) found higher volatile concentrations in the headspace of a coarse emulsion, compared to a homogenized fine emulsion, indicating a the weaker retention of volatiles in the coarse emulsion. This is also comparable to the effect of droplet size on the partitioning of hydrophobic compounds in emulsions found in our present work.

\subsection{Carvacrol partitioning in lipid and aqueous phase of emulsions}

The distribution of carvacrol between oil and aqueous region was studied to further understand its behavior when exposed to a multiphase food matrix. Fig. 5 shows the partition coefficients $(\log K)$ of carvacrol in samples at the equilibrium, calculated using Eq. (4). The partition coefficient of carvacrol reached a constant value after day 5 (no significant difference between day 5 and day 7 was found $(p>0.05)$ ), indicating that an equilibrium (or at least a pseudoequilibrium) of the carvacrol concentrations in the creamed and aqueous phases was reached. The $\log K$ 's for fine emulsions were significantly lower than those for the coarse emulsion and separate layer system at day 5 and $7(p<0.05$ ), owing to the promoted contact of the oil with the headspace in the latter cases (creamed droplet layer, or non-emulsified oil layer, respectively). Within the fine emulsions, the $\log K$ of carvacrol was significant higher in the XS-sized emulsion than in the S- and M-sized emulsions, both at day 5 and day $7(p<0.05)$. This suggests that a small oil droplet size promotes the absorption of carvacrol in the lipid droplet phase. When a simple WPI solution (1.5 wt $\%$ ) was used (i.e., no oil in the system), a linear increase of the carvacrol concentration in the WPI solution was observed during incubation $\left(\mathrm{R}^{2}=0.9953\right)$, and at day 7 a 4 -fold higher carvacrol concentration was measured in this WPI solution compared to the aqueous phase of emulsions and of the separate layer system (Supplementary Fig. 1). This indicates that when an oil phase was present, the concentration of carvacrol in the available aqueous environment did not reach

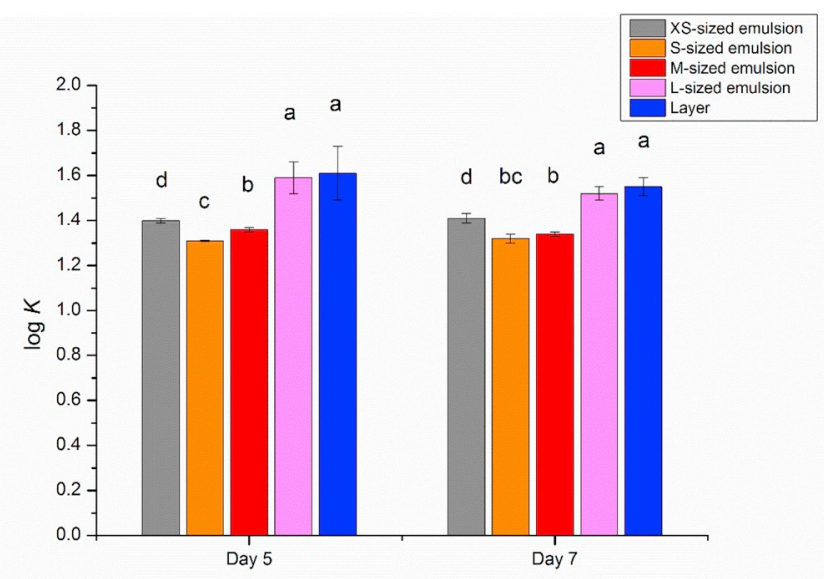

Fig. 5. Partition coefficient $(\log K)$ of carvacrol between the oil/creamed and aqueous phases of the samples. The higher the $\log K$, the stronger the partitioning of carvacrol in the oil/creamed phase at the expense of the aqueous phase.

saturation, most likely because carvacrol is largely hydrophobic.

These results can be explained by the fact that the partitioning behaviour was led by the interactions of carvacrol with the different components of each available phase (Asnaashari, Farhoosh, \& Sharif, 2014; Di Mattia, Sacchetti, Mastrocola, \& Pittia, 2009). Carvacrol is expected to be absorbed in both lipid and aqueous phases, as the lipid (droplet) phase is composed of triglycerides and adsorbed whey proteins, and the aqueous phase of water and free whey proteins. It could even be relevant to consider the protein-stabilized interface as a separate pseudophase of the system, in a comparable manner to the model proposed by the group of Romsted and Bravo-Díaz (2013), although this was developed and validated for surfactant-based emulsions. Compared with the $\log P$ of carvacrol determined between octanol and water ( $\log P=3.52$ (Ben Arfa et al., 2006), we obtained a lower $\log K$ of carvacrol between the creamed and aqueous phases in all samples. This may be explained via different mechanisms. First, in our systems, the free WPI present in the aqueous phase can also bind hydrophobic compounds. In addition, the partitioning of carvacrol is determined by the nature of the oil phase, i.e., octanol or triglyceride oil (Niimi, 1991). The migration rate and eventual partitioning of carvacrol initially loaded in a CAR-PLA film may be important to understand its antimicrobial efficiency in emulsions, and more generally in multiphase foods. In fact, as bacteria grow in aqueous phase environments, the 
A

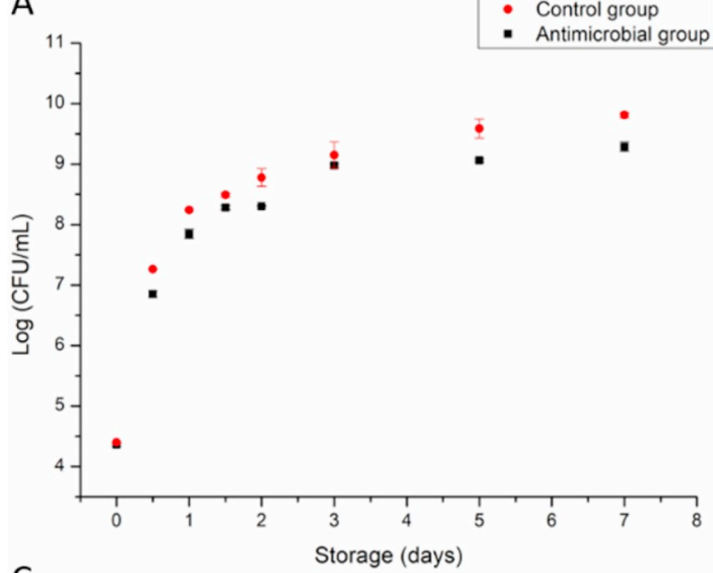

C

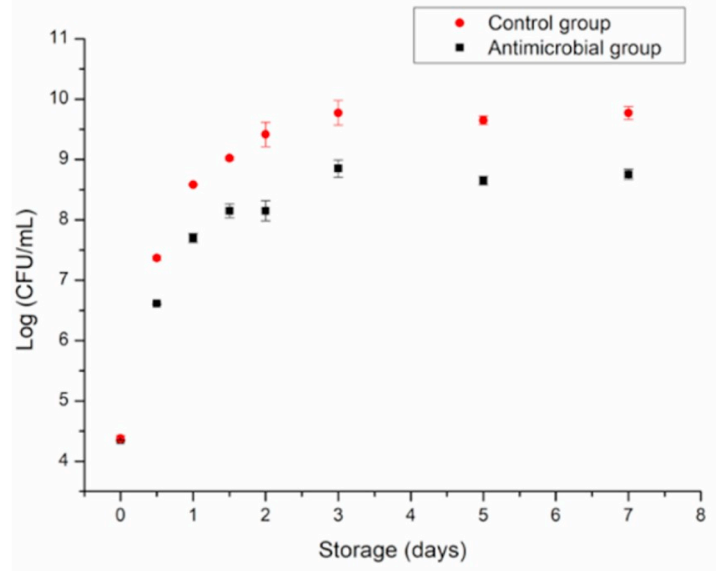

B

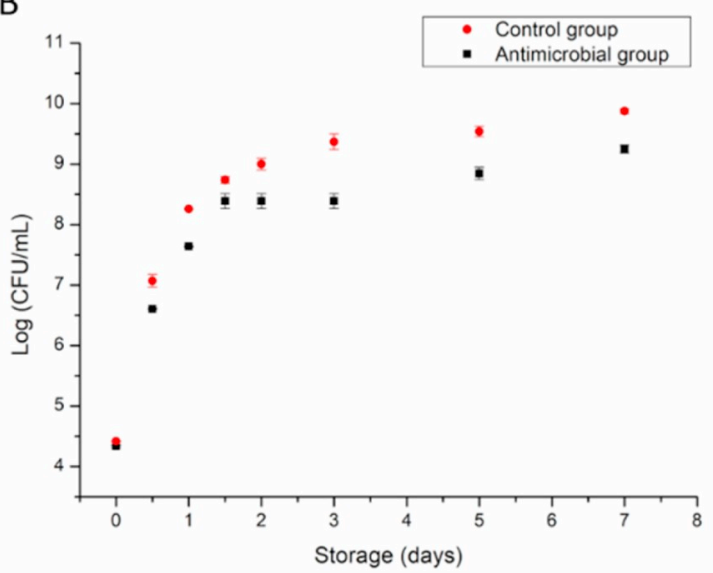

Fig. 6. Growth curves of Pseudomonas fluorescens in (A) XS-sized emulsion (B) S-sized emulsion (C) M-sized emulsion in antimicrobial/control group at $20{ }^{\circ} \mathrm{C}$.

proportion of antimicrobial in lipid/aqueous region can influence bacteria inhibition during storage.

\subsection{Antimicrobial effect of the CAR-PLA film and modelling of bacterial growth curve}

The growth of a model spoilage bacteria in fine emulsion samples exposed to carvacrol (with CAR-PLA film) or not (without CAR-PLA film) is presented in Fig. 6. In the M-sized emulsion, the presence of the CAR-PLA film in the vial resulted in a significant reduction of $1.02 \pm 0.09 \log \mathrm{CFU} / \mathrm{mL}$ of the Pseudomonas fluorescens population at day 7, by comparison with the control system incubated without the CAR-PLA film $(p<0.05)$. In the S- and XS-sized emulsions, inhibition of the bacterial growth induced by the presence of the CAR-PLA film was also found, although to a lesser extent (significant reduction of $0.62 \pm 0.05$ and $0.52 \pm 0.06 \log$ at day 7 , respectively).

The bacterial growth data were fitted with a modified Gompertz model by non-linear regression. The model showed a good fit as can be seen from the small size of the residuals (average deviation 6.7\%) and the low sum of squares of residuals $(<6.67)$. The maximum growth rate $\left(u_{\max }\right)$ and the logarithm of the asymptotic values of the relative population size $\left(A_{s}\right)$ were estimated; no lag phase was observed $(\lambda=0)$ for all conditions (Table 2). The growth of bacteria in XS- and S-sized emulsions did not reach to the asymptotic population size during incubation, yet a slight increase in the population size was found after day 5 in both samples, thus we only estimated the asymptotic population size in M-sized emulsions. The results showed that the asymptotic population size for antimicrobial-exposed samples (9.68 $\pm 0.27 \log \mathrm{CFU} /$
$\mathrm{mL}$ ) was significantly lower than the values found in control groups $(12.01 \pm 0.31 \log \mathrm{CFU} / \mathrm{mL})(p<0.05)$ in M-sized emulsions. Besides, for this emulsion, the maximum growth rate was significantly lower in the antimicrobial-exposed sample compared to the control group $(p<0.05)$. However, in the S- and XS-sized emulsion, the presence of the CAR-PLA film in the closed vial did not significantly lower $u_{\max }$ during incubation, revealing a weak antimicrobial effect of carvacrol.

It can be concluded from the bacterial reduction values and the estimated $A_{s}$ and $u_{\max }$ that amongst the three fine emulsions tested, the antimicrobial effect of the CAR-PLA film was the greatest in the emulsion containing relatively large oil droplets (M-sized emulsion). This finding can be explained by the partition behavior of carvacrol between the creamed and aqueous phases. The Log $K$ of carvacrol in the XS-sized emulsion was relatively high, compared to that in the S- and M-sized emulsions, indicating that more carvacrol was proportionally absorbed in the droplet phase in the XS-sized emulsion. It is possible that the incorporation of carvacrol in the lipid droplet phase segregates it from the bacteria which are present in the aqueous phase, thus resulting in a lower antimicrobial efficiency. Many studies have reported that antimicrobial activity is often low in food matrices with high fat content, as the high solubility of antimicrobials in the fat phase impedes the interplay between these agents and bacteria. For example, Gaysinsky, Taylor, Davidson, Bruce, and Weiss (2007) found that the minimum inhibitory concentrations against food pathogens significantly increased with the increase of fat content in milk. SmithPalmer, Stewart, and Fyfe (2001) concluded that the direct addition of thyme essential oil in foods had less antimicrobial effect on full-fat soft cheese than on low-fat soft cheese. However, the antimicrobial 
Table 2

Estimated growth rate as calculated from a modified Gompertz equation fitted to the Pseudomonas fluorescens experimental plate counts in fine emulsions stored at $20{ }^{\circ} \mathrm{C}$.

\begin{tabular}{|c|c|c|c|c|c|c|}
\hline \multirow[t]{2}{*}{ Parameters } & \multicolumn{2}{|l|}{ XS-sized emulsion } & \multicolumn{2}{|l|}{ S-sized emulsion } & \multicolumn{2}{|l|}{ M-sized emulsion } \\
\hline & Antimicrobial group & Control group & Antimicrobial group & Control group & Antimicrobial group & Control group \\
\hline Maximum specific growth rate $\left(\right.$ days $^{-1}$ ) & $9.71 \pm 1.25^{\mathrm{a}}$ & $11.26 \pm 1.71^{\mathrm{a}}$ & $9.10 \pm 0.97^{\mathrm{a}}$ & $10.52 \pm 1.21^{\mathrm{a}}$ & $9.40 \pm 0.86^{\mathrm{a}}$ & $12.42 \pm 0.86^{\mathrm{b}}$ \\
\hline Sum of squares of residuals $\left(S S_{r e s}\right)$ & 4.42 & 6.67 & 3.05 & 4.38 & 1.91 & 2.65 \\
\hline
\end{tabular}

Different letters (a and b) indicate significant differences between the antimicrobial and control group $(p<0.05)$.

activities on the emulsions with a fixed fraction of oil but various oil droplet sizes had not been reported yet, and we herein show that the oil droplet size modulates the efficiency of antimicrobial agents.

\section{Conclusion}

This study demonstrates that the oil droplet size in emulsions has an impact on the partitioning and antimicrobial activity of carvacrol initially loaded in a food packaging film. Emulsions with a large interfacial area (very small droplets) absorbed a significantly higher carvacrol amount than emulsions with smaller interfacial areas (larger droplets). This trend is, however, only applicable until a certain droplet size, above which droplet creaming becomes substantial over the timescale of the experiment. Decreasing oil droplet size increased the partitioning of the absorbed carvacrol towards the lipid droplet phase, at the expense of the aqueous phase, which decreased the antimicrobial efficacy of CAR-PLA film. This work provides insightful information for the application of antimicrobials in food emulsions: the effect of antimicrobial-based AP depends more on the spatial distribution of the absorbed antimicrobial molecules within the emulsion, rather than on the total amount absorbed.

\section{CRediT authorship contribution statement}

Li Wang: Conceptualization, Methodology, Investigation, Writing original draft. Matthijs Dekker: Conceptualization, Supervision, Writing - review \& editing. Jenneke Heising: Conceptualization, Supervision, Writing - review \& editing. Vincenzo Fogliano: Conceptualization, Supervision, Writing - review \& editing. Claire C. Berton-Carabin: Writing - review \& editing, Supervision, Conceptualization.

\section{Declaration of competing interest}

None.

\section{Acknowledgement}

The authors thank to the China Scholarship Council for supporting a PhD fellowship for L.Wang. We would also like to acknowledge the Wageningen Food \& Biobased Research for providing the PLA (4043D Ingeo $\left.^{\mathrm{TM}}\right)$.

\section{Appendix A. Supplementary data}

Supplementary data to this article can be found online at https:// doi.org/10.1016/j.foodcont.2020.107247.

\section{References}

Ahmed, J., Hiremath, N., \& Jacob, H. (2016). Antimicrobial, rheological, and thermal properties of plasticized polylactide films incorporated with essential oils to Inhibit Staphylococcus aureus and Campylobacter jejuni. Journal of Food Science, 81(2), E419-E429. https://doi.org/10.1111/1750-3841.13193.

Altan, A., Aytac, Z., \& Uyar, T. (2018). Carvacrol loaded electrospun fibrous films from zein and poly (lactic acid) for active food packaging. Food Hydrocolloids, 81, 48-59. https://doi.org/10.1016/j.foodhyd.2018.02.028.

Arora, D. S., \& Kaur, J. (1999). Antimicrobial activity of spices. International Journal of Antimicrobial Agents, 12(3), 257-262. https://doi.org/10.1016/S0924-8579(99) 00074-6.

Asnaashari, M., Farhoosh, R., \& Sharif, A. (2014). Antioxidant activity of gallic acid and methyl gallate in triacylglycerols of Kilka fish oil and its oil-in-water emulsion. Food Chemistry, 159, 439-444. https://doi.org/10.1016/j.foodchem.2014.03.038.

de Azeredo, H. M. (2013). Antimicrobial nanostructures in food packaging. Trends in Food Science \& Technology, 30(1), 56-69. https://doi.org/10.1016/j.tifs.2012.11.006.

Becher, P. (2001). Emulsion applications. Emulsions: Theory and Practice, 429-459.

Ben Arfa, A., Combes, S., Preziosi-Belloy, L., Gontard, N., \& Chalier, P. (2006). Antimicrobial activity of carvacrol related to its chemical structure. Letters in Applied Microbiology, 43(2), 149-154. https://doi.org/10.1111/j.1472-765X.2006.01938.x.

Benjamin, O., Silcock, P., Leus, M., \& Everett, D. (2012). Multilayer emulsions as delivery systems for controlled release of volatile compounds using $\mathrm{pH}$ and salt triggers. Food Hydrocolloids, 27(1), 109-118. https://doi.org/10.1016/j.foodhyd.2011.08.008.

Berton-Carabin, C. C., \& Schroën, K. (2015). Pickering emulsions for food applications: Background, trends, and challenges. Annual Review of Food Science and Technology, 6, 263-297. https://doi.org/10.1146/annurev-food-081114-110822.

Berton, C., Genot, C., \& Ropers, M.-H. (2011). Quantification of unadsorbed protein and surfactant emulsifiers in oil-in-water emulsions. Journal of Colloid and Interface Science, 354(2), 739-748. https://doi.org/10.1016/j.jcis.2010.11.055.

Berton, C., Ropers, M.-H., Viau, M., \& Genot, C. (2011). Contribution of the interfacial layer to the protection of emulsified lipids against oxidation. Journal of Agricultural and Food Chemistry, 59(9), 5052-5061. https://doi.org/10.1021/jf200086n.

Borges, M., Díaz, L., Alvarez-Galván, M., \& Brito, A. (2011). High performance heterogeneous catalyst for biodiesel production from vegetal and waste oil at low temperature. Applied Catalysis B: Environmental, 102(1-2), 310-315. https://doi.org/10. 1016/j.apcatb.2010.12.018.

Carey, M. E., Asquith, T., Linforth, R. S., \& Taylor, A. J. (2002). Modeling the partition of volatile aroma compounds from a cloud emulsion. Journal of Agricultural and Food Chemistry, 50(7), 1985-1990. https://doi.org/10.1021/jf011044+.

Daferera, D. J., Ziogas, B. N., \& Polissiou, M. G. (2003). The effectiveness of plant essential oils on the growth of Botrytis cinerea, Fusarium sp. and Clavibacter michiganensis subsp. michiganensis. Crop Protection, 22(1), 39-44. https://doi.org/10.1016/S02612194(02)00095-9.

Di Mattia, C. D., Sacchetti, G., Mastrocola, D., \& Pittia, P. (2009). Effect of phenolic antioxidants on the dispersion state and chemical stability of olive oil O/W emulsions. Food Research International, 42(8), 1163-1170. https://doi.org/10.1016/j. foodres.2009.05.017.

Doi, T., Wang, M., \& McClements, D. J. (2019). Impact of proteins and polysaccharides on flavor release from oil-in-water emulsions during simulated cooking. Food Research International, 125, 108549. https://doi.org/10.1016/j.foodres.2019.108549.

Dresselhuis, D. M., Stuart, M. A. C., van Aken, G. A., Schipper, R. G., \& de Hoog, E. H. (2008). Fat retention at the tongue and the role of saliva: Adhesion and spreading of 'protein-poor'versus 'protein-rich'emulsions. Journal of Colloid and Interface Science, 321(1), 21-29. https://doi.org/10.1016/j.jcis.2008.01.051.

FAO, G. (2011). Global food losses and food waste-Extent, causes and prevention. SAVE FOOD: An initiative on Food Loss and Waste Reduction.

Gaysinsky, S., Taylor, T. M., Davidson, P. M., Bruce, B. D., \& Weiss, J. (2007). Antimicrobial efficacy of eugenol microemulsions in milk against Listeria monocytogenes and Escherichia coli O157: H7. Journal of Food Protection, 70(11), 2631-2637. https://doi.org/10.4315/0362-028X-70.11.2631.

Han, J. H. (2003). Antimicrobial food packaging. Novel Food Packaging Techniques, 8, 50-70.

Higueras, L., López-Carballo, G., Hernández-Muñoz, P., Catalá, R., \& Gavara, R. (2014). Antimicrobial packaging of chicken fillets based on the release of carvacrol from chitosan/cyclodextrin films. International Journal of Food Microbiology, 188, 53-59. https://doi.org/10.1016/j.ijfoodmicro.2014.07.018.

Jafari, S. M., Assadpoor, E., He, Y., \& Bhandari, B. (2008). Re-coalescence of emulsion droplets during high-energy emulsification. Food Hydrocolloids, 22(7), 1191-1202. https://doi.org/10.1016/j.foodhyd.2007.09.006.

Jideani, V. A., \& Vogt, K. (2016). Antimicrobial packaging for extending the shelf life of bread-a review. Critical Reviews in Food Science and Nutrition, 56(8), 1313-1324. https://doi.org/10.1080/10408398.2013.768198.

Keppler, J. K., Steffen-Heins, A., Berton-Carabin, C. C., Ropers, M.-H., \& Schwarz, K. (2018). Functionality of whey proteins covalently modified by allyl isothiocyanate. Part 2: Influence of the protein modification on the surface activity in an $\mathrm{O} / \mathrm{W}$ system. Food Hydrocolloids, 81, 286-299. https://doi.org/10.1016/j.foodhyd.2018.03.003.

Lu, J., Pickova, J., Vázquez-Gutiérrez, J. L., \& Langton, M. (2018). Influence of seasonal variation and ultra high temperature processing on lipid profile and fat globule 
structure of Swedish cow milk. Food Chemistry, 239, 848-857. https://doi.org/10. 1016/j.foodchem.2017.07.018.

Mascheroni, E., Chalier, P., Gontard, N., \& Gastaldi, E. (2010). Designing of a wheat gluten/montmorillonite based system as carvacrol carrier: Rheological and structural properties. Food Hydrocolloids, 24(4), 406-413. https://doi.org/10.1016/j.foodhyd. 2009.11.007.

McClements, D. J. (2004). Protein-stabilized emulsions. Current Opinion in Colloid \& Interface Science, 9(5), 305-313. https://doi.org/10.1016/j.cocis.2004.09.003.

McClements, D. J. (2005). Theoretical analysis of factors affecting the formation and stability of multilayered colloidal dispersions. Langmuir, 21(21), 9777-9785. https:// doi.org/10.1021/la0512603.

McClements, D. J. (2015). Food emulsions: Principles, practices, and techniques. CRC press. Mihindukulasuriya, S., \& Lim, L.-T. (2014). Nanotechnology development in food packaging: A review. Trends in Food Science \& Technology, 40(2), 149-167. https:// doi.org/10.1016/j.tifs.2014.09.009.

Mlalila, N., Hilonga, A., Swai, H., Devlieghere, F., \& Ragaert, P. (2018). Antimicrobial packaging based on starch, poly (3-hydroxybutyrate) and poly (lactic-co-glycolide) materials and application challenges. Trends in Food Science \& Technology, 74, 1-11. https://doi.org/10.1016/j.tifs.2018.01.015.

Niimi, A. (1991). Solubility of organic chemicals in octanol, triolein and cod liver oil and relationships between solubility and partition coefficients. Water Research, 25(12), 1515-1521. https://doi.org/10.1016/0043-1354(91)90182-P.

Periago, P. M., Delgado, B., Fernández, P. S., \& Palop, A. (2004). Use of carvacrol and cymene to control growth and viability of Listeria monocytogenes cells and predictions of survivors using frequency distribution functions. Journal of Food Protection, 67(7), 1408-1416. https://doi.org/10.4315/0362-028X-67.7.1408.

Quintavalla, S., \& Vicini, L. (2002). Antimicrobial food packaging in meat industry. Meat Science, 62(3), 373-380. https://doi.org/10.1016/S0309-1740(02)00121-3.

Rhim, J. W., Mohanty, A. K., Singh, S. P., \& Ng, P. K. (2006). Effect of the processing methods on the performance of polylactide films: Thermocompression versus solvent casting. Journal of Applied Polymer Science, 101(6), 3736-3742. https://doi.org/10. 1002/app. 23403.

Romsted, L. S., \& Bravo-Díaz, C. (2013). Modeling chemical reactivity in emulsions. Current Opinion in Colloid \& Interface Science, 18(1), 3-14. https://doi.org/10.1016/j. cocis.2012.11.001.

de Roos, K. B. (2003). Effect of texture and microstructure on flavour retention and release. International Dairy Journal, 13(8), 593-605. https://doi.org/10.1016/s09586946(03)00108-0.

Smith-Palmer, A., Stewart, J., \& Fyfe, L. (2001). The potential application of plant essential oils as natural food preservatives in soft cheese. Food Microbiology, 18(4), 463-470. https://doi.org/10.1046/j.1365-2672.1999.00525.x.

Soottitantawat, A., Yoshii, H., Furuta, T., Ohkawara, M., \& Linko, P. (2003). Microencapsulation by spray drying: Influence of emulsion size on the retention of volatile compounds. Journal of Food Science, 68(7), 2256-2262. https://doi.org/10. 1111/j.1365-2621.2003.tb05756.x.

Stokes, G. G. (1851). On the effect of the internal friction of fluids on the motion of pendulums. Cambridge: Pitt Press.

Sung, S.-Y., Sin, L. T., Tee, T.-T., Bee, S.-T., Rahmat, A., Rahman, W., ... Vikhraman, M (2013). Antimicrobial agents for food packaging applications. Trends in Food Science \& Technology, 33(2), 110-123. https://doi.org/10.1016/j.tifs.2013.08.001.

Tunc, S., Duman, O., \& Polat, T. G. (2016). Effects of montmorillonite on properties of methyl cellulose/carvacrol based active antimicrobial nanocomposites. Carbohydrate Polymers, 150, 259-268. https://doi.org/10.1016/j.carbpol.2016.05.019.

Weiss, J., Loeffler, M., \& Terjung, N. (2015). The antimicrobial paradox: Why preservatives lose activity in foods. Current Opinion in Food Science, 4, 69-75. https://doi. org/10.1016/j.cofs.2015.05.008.

Yucel, U., Elias, R. J., \& Coupland, J. N. (2012). Solute distribution and stability in emulsion-based delivery systems: An EPR study. Journal of Colloid and Interface Science, 377(1), 105-113. https://doi.org/10.1016/j.jcis.2012.03.071.

Zwietering, M., Jongenburger, I., Rombouts, F., \& Van't Riet, K. (1990). Modeling of the bacterial growth curve. Applied and Environmental Microbiology, 56(6), 1875-1881. 